\title{
Consistency of effect of ezetimibe/simvastatin compared with intensified lipid-lowering treatment strategies in obese and non-obese diabetic subjects
}

\author{
Jeffrey B Rosen ${ }^{1 *}$, Jose G Jimenez ${ }^{2}$, Valdis Pirags ${ }^{3}$, Hella Vides ${ }^{4}$, Rachid Massaad ${ }^{5}$, Mary E Hanson ${ }^{6}$, \\ Philippe Brudi ${ }^{6}$ and Joseph Triscari ${ }^{6}$
}

\begin{abstract}
Purpose: This post hoc analysis assessed switching to ezetimibe/simvastatin 10/20 mg vs doubling the baseline statin dose to simvastatin $40 \mathrm{mg}$ or atorvastatin $20 \mathrm{mg}$ or switching to rosuvastatin $10 \mathrm{mg}$ in subgroups of obese $\left(\mathrm{BMl} \geq 30 \mathrm{~kg} / \mathrm{m}^{2}\right)$ and non-obese $\left(\mathrm{BMl}<30 \mathrm{~kg} / \mathrm{m}^{2}\right)$ diabetic subjects.

Methods: This was a randomized, double-blind, 12-week study of adults 18-79 years with cardiovascular disease with low-density lipoprotein cholesterol $(\mathrm{LDL}-\mathrm{C}) \geq 70$ and $\leq 160 \mathrm{mg} / \mathrm{dl}$. Percent change in $\mathrm{LDL}-\mathrm{C}$ and other lipids was estimated.
\end{abstract}

Results: In obese subjects ( $n=466)$, percent changes in LDL-C and most other lipids were greater with ezetimibe/ simvastatin vs doubling the baseline statin dose or switching to rosuvastatin. In non-obese subjects $(n=342)$, percent changes in LDL-C, total cholesterol, non-HDL-C, Apo B and Apo A-I were greater with ezetimibe/simvastatin vs doubling the baseline statin dose or switching to rosuvastatin; and treatment with ezetimibe/simvastatin resulted in greater changes in triglycerides vs rosuvastatin and HDL-C vs doubling the baseline statin dose. The safety profiles were generally similar.

Conclusions: Regardless of baseline obesity status, switching to ezetimibe/simvastatin was more effective at reducing LDL-C, total cholesterol, non-HDL-C, and Apo B vs doubling the baseline statin dose to simvastatin $40 \mathrm{mg}$ or atorvastatin $20 \mathrm{mg}$ or switching to rosuvastatin $10 \mathrm{mg}$.

Keywords: Atorvastatin, Ezetimibe, Diabetes, Obesity, Rosuvastatin, Statin

\section{Background}

The presence of diabetes and obesity is associated with an increased risk of cardiovascular disease (CVD) [1-3]. Recommendations from the US, Canadian, and European treatment guidelines focus on reducing LDL-C to $<70 \mathrm{mg} /$ $\mathrm{dL}(<1.81 \mathrm{mmol} / \mathrm{L})$ for high risk patients with diabetes and cardiovascular disease (CVD) [4-6]. However, in obese individuals, when dyslipidemia is present it is often characterized by decreased HDL-C and increased non-HDL-C, triglycerides, apolipoprotein (Apo) B and small, dense LDL$\mathrm{C}$ particles, although often, relatively normal levels of LDL-

\footnotetext{
* Correspondence: JBRcrsf@aol.com

'Clinical Research of South Florida, Coral Gables, FL, USA

Full list of author information is available at the end of the article
}

C $[7,8]$. Likewise, the dyslipidemia associated with diabetes is characterized by a similar lipid profile [9]. As a result, individuals with diabetes and/or obesity with dyslipidemia may be undertreated even after intense lipid-lowering therapy [9]. The use of combination therapies may be warranted to achieve optimal lipid and lipoprotein levels, as well as treatment targets for Apo B and non-HDL-C, as recommended by the American Diabetes Association and American College of Cardiology consensus statement for patients with elevated cardiometabolic risk [9].

Clinical trials done in diabetic subjects have shown that the combination of ezetimibe/simvastatin provides additional lipid reductions over simvastatin and atorvastatin monotherapy $[10,11]$. It has also been shown that

\section{Biomed Central}


a higher proportion of high risk CVD patients, including those with diabetes, achieve target LDL-C levels when treated with the combination of ezetimibe/simvastatin $10 / 40 \mathrm{mg}$ compared with switching to atorvastatin $40 \mathrm{mg}$ or rosuvastatin 5-10 $\mathrm{mg}$ [12]. In addition, a pooled analysis of 27 studies that grouped subjects by baseline diabetic status (with or without diabetes) showed that the lipid profile in subjects with diabetes improved to a greater extent than in subjects without diabetes after treatment with the combination of ezetimibe/statin [13]. However, data assessing the effect of lipid lowering therapies in obese and non-obese diabetic patients are limited.

The primary objective of this post hoc analysis was to assess the consistency of treatment effect of switching to ezetimibe/simvastatin 10/20 mg vs. doubling the baseline statin dose to simvastatin $40 \mathrm{mg}$ or atorvastatin $20 \mathrm{mg}$ in subgroups of obese diabetic subjects $(n=466)$ and non-obese diabetic subjects $(\mathrm{n}=342)$ based on body mass index $(\mathrm{BMI}) \geq 30 \mathrm{~kg} / \mathrm{m}^{2}$ or $<30 \mathrm{~kg} / \mathrm{m}^{2}$. The secondary objective was to perform a similar post hoc analysis as the primary for the comparison of ezetimibe/simvastatin $10 / 20 \mathrm{mg}$ vs switching to rosuvastatin $10 \mathrm{mg}$ in the same subgroups of subjects. Tolerability was also assessed.

\section{Methods}

This was a post hoc analysis of a randomized, doubleblind, 12-week study in subgroups of obese and non-obese diabetic subjects based on body mass index $\geq 30 \mathrm{~kg} / \mathrm{m}^{2}$ or $<30 \mathrm{~kg} / \mathrm{m}^{2}$ (Protocol 133; clinical trials registry NCT 00862251) [14]. The study was carried out between June 2009 and March 2011 in 86 centers in Austria, Bulgaria, Chile, Costa Rica, Croatia, Egypt, Estonia, Germany, Greece, Hungary, Italy, Latvia, Lithuania, Peru, Portugal, and the United States and was conducted in conformance with Good Clinical Practice standards and applicable country and/or local statutes and regulations regarding ethical committee review, informed consent, and the protection of human subjects participating in biomedical research.

\section{Subjects}

Eligible subjects were non-Asian males or females, $\geq 18$ and $<80$ years, with type 1 or type 2 diabetes mellitus (HbA1c $\leq 8.5 \%)$ and symptomatic/overt CVD who were naive to statin and/or ezetimibe or were taking a stable dose of approved lipid-lowering therapy (simvastatin 10 or $20 \mathrm{mg}$; atorvastatin $10 \mathrm{mg}$; pravastatin 10,20 or $40 \mathrm{mg}$; fluvastatin 20, 40 or $80 \mathrm{mg}$, ezetimibe $10 \mathrm{mg}$; lovastatin $10,20,40$ or $80 \mathrm{mg}$, or ezetimibe + fluvastatin 10 or $20 \mathrm{mg}$ ) and if needed, taking a stable anti-diabetic medication for 3 months prior to the screening visit. Subjects must have been willing to maintain a cholesterol- and glucose-lowering diet for the duration of the study. Prior to randomization subjects were required to complete the screening/stabilization period on simvastatin $20 \mathrm{mg}$ or atorvastatin $10 \mathrm{mg}$ with $\mathrm{LDL}-\mathrm{C} \geq 70 \mathrm{mg} / \mathrm{dl}(1.81 \mathrm{mmol} / \mathrm{L})$ and $\leq 160 \mathrm{mg} / \mathrm{dl}(4.14 \mathrm{mmol} / \mathrm{L})$, alanine transaminase (ALT) and aspartate aminotransferase (AST) $\leq 2.0 \times$ upper limit of normal (ULN) (no active liver disease), creatine kinase $(\mathrm{CK}) \leq 3 \times \mathrm{ULN}$, and triglycerides $\leq 400 \mathrm{mg} / \mathrm{dl}$ (4.52 mmol/L). Subjects were excluded if they were Asian, since rosuvastatin prescribing information recommends a $5 \mathrm{mg}$ starting dose for Asians. Subjects were also excluded if they had uncontrolled endocrine or metabolic disease that impacted lipids/lipoproteins, uncontrolled or recentonset diabetes, congestive heart failure, hypertension, digestive disease/intestinal malabsorption, were taking agents impacting lipids, potent CYP3A4 inhibitors, $>1$ quart/day grapefruit juice, systemic corticosteroids, cyclosporine, danazol or fusidic acid, agents increasing risk of myopathy, or warfarin.

\section{Randomization and blinding}

After a 6-week run-in period of simvastatin $20 \mathrm{mg}$ or atorvastatin $10 \mathrm{mg}$ (baseline statin doses), subjects with LDL-C $\geq 70 \mathrm{mg} / \mathrm{dL}(1.81 \mathrm{mmol} / \mathrm{L})$ and $\leq 160 \mathrm{mg} / \mathrm{dL}$ $(4.14 \mathrm{mmol} / \mathrm{L})$ were stratified according to their baseline statin and randomized in a 2:1:2 ratio within strata to ezetimibe/simvastatin $10 / 20 \mathrm{mg}$, doubling their baseline statin, or rosuvastatin $10 \mathrm{mg}$ for 6 weeks using an interactive voice response system. Subjects who met eligibility criteria at the screening visit were provided with openlabel simvastatin $20 \mathrm{mg}$ or atorvastatin $10 \mathrm{mg}$ tablets. At randomization, subjects were supplied in a double dummy fashion with bottles of blinded ezetimibe/simvastatin 10/ $20 \mathrm{mg}$ or matching placebo and rosuvastatin $10 \mathrm{mg}$ or matching placebo. A blocked randomization was used with a block size of 5 . Subjects, investigators, and study personnel involved in the study remained blinded during the study period until the data were complete and clean and a database lock was obtained.

\section{Efficacy endpoints}

In this post hoc analysis, the primary evaluation was the consistency of the treatment effect between ezetimibe/ simvastatin 10/20 mg vs. doubling the baseline statin dose across subgroups (obese/non-obese) and the secondary evaluation was the consistency of the treatment effect between ezetimibe/simvastatin $10 / 20 \mathrm{mg}$ vs. rosuvastatin $10 \mathrm{mg}$ across subgroups (obese/non-obese). Efficacy endpoints of interest were the percent change from baseline in low density lipoprotein cholesterol (LDL-C), total cholesterol, triglycerides, high-density lipoprotein cholesterol (HDL-C), non-HDL-C, Apo B, Apo A-I, high-sensitivity $\mathrm{C}$-reactive protein (hs-CRP), LDL-C/HDL-C ratio, total cholesterol/HDL-C ratio, non-HDL-C/HDL-C ratio, and Apo B/Apo A-I ratio at Week 6. The percent of patients achieving LDL-C $<70 \mathrm{mg} / \mathrm{dl}$ (1.81 mmol/l), non-HDL-C 
$<100 \mathrm{mg} / \mathrm{dl}(2.59 \mathrm{mmol} / \mathrm{l})$, or Apo B $<80 \mathrm{mg} / \mathrm{dl}(0.80 \mathrm{~g} / \mathrm{L})$ was assessed at Week 6 .

\section{Safety endpoints}

Prespecified adverse events (AEs) of interest were gastrointestinal-related, gallbladder-related, allergic reaction/rash-related, and hepatitis-related AEs; consecutive elevations in alanine aminotransferase (ALT) / aspartate aminotransferase (AST) $\geq 3 \times$ ULN, $\geq 5 \times$ ULN, and $\geq 10 \times$ ULN; consecutive elevations in ALT and/or AST $\geq 3 \mathrm{x}$ ULN, $\geq 5 \times$ ULN and $\geq 10 \times$ ULN, elevations in ALT or AST $\geq 3 \times$ ULN, elevations in CK $\geq 10 \times$ ULN, elevations in CK $\geq 10 \times$ ULN with muscle symptoms, and elevations in CK $\geq 10 \times$ ULN with muscle symptoms that are considered drug-related. In addition, the broad $\mathrm{AE}$ categories consisting of the percentage of patients with any $\mathrm{AE}$, a drugrelated $\mathrm{AE}$, a serious $\mathrm{AE}$, a serious drug-related $\mathrm{AE}$, and who discontinued due to an $\mathrm{AE}$ were assessed.

\section{Statistics}

The full analysis set (FAS), which included all randomized patients who took at least 1 dose of study drug and had a baseline measurement, was used for the efficacy analyses. The all-patients-as-treated (APaT) approach was used for the safety analyses, and included all randomized patients receiving $\geq 1$ dose of study drug and all safety data up to 14 days after the last intake of study medication. At least 1 laboratory/vital sign measurement was required subsequent to at least 1 dose of study treatment for inclusion in the analysis of each specific parameter. The estimate of the within-group treatment effect, and the between-group treatment effect with a nominal 95\% confidence interval for the efficacy variables was estimated within each subgroup (i.e., obese/non-obese) using a constrained longitudinal data analysis model applied to each subgroup separately, with terms for treatment, time, timeby-treatment interaction, stratum, and time-by-stratum interaction. As some deviation from normality was observed for the percent change from baseline in LDL-C, a similar post hoc sensitivity analysis on log-transformed data, as done for the overall population, was performed to corroborate the main analysis on un-transformed data [14]. For AEs of interest and broad AE categories, count and \% of patients with AEs were provided by treatment group within each subgroup.

\section{Results}

The flow of subjects through the study is shown in Figure 1. Of the 808 subjects that were randomized, 466 $(57.7 \%)$ were included in the obese subgroup and 342 $(42.3 \%)$ were included in the non-obese subgroup. Within the obese subgroup, 181 (38.8\%) were randomized to ezetimibe/simvastatin, 93 (20.0\%) were randomized to have their statin dose doubled and 192 (41.2\%) were randomized

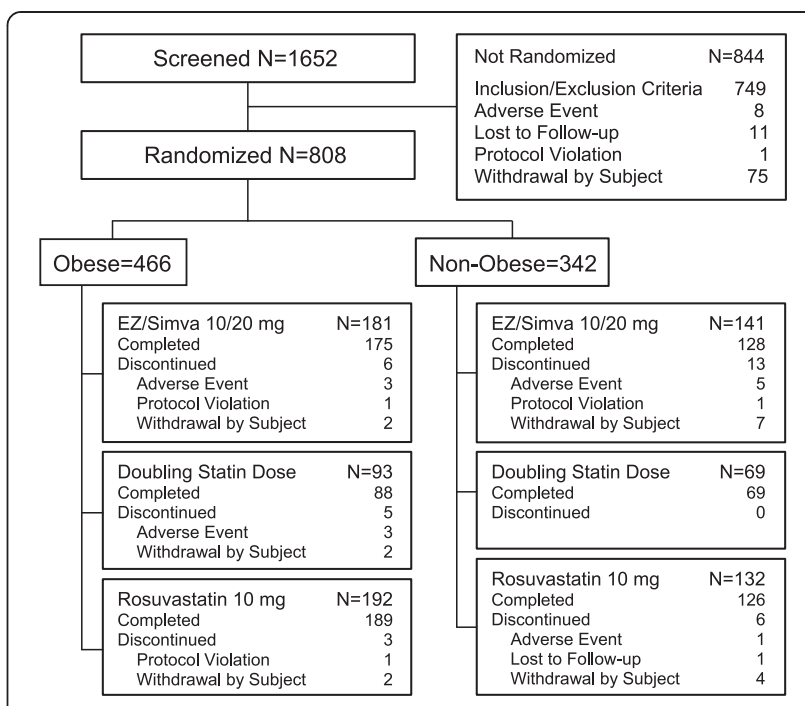

Figure 1 Flow of subjects through the study.

to rosuvastatin $10 \mathrm{mg}$. Within the non-obese subgroup, 141 (41.2\%) were randomized to ezetimibe/simvastatin, 69 (20.2\%) were randomized to have their statin dose doubled and $132(38.6 \%)$ were randomized to rosuvastatin $10 \mathrm{mg}$

Baseline demographics and clinical characteristics were generally similar between obese and non-obese subjects with a few exceptions (Table 1). In obese subjects, the mean age $( \pm \mathrm{SD})$ was $\sim 63( \pm 8)$ years and the majority of subjects were Caucasian in all 3 treatment groups. In the subgroup of obese subjects, the rosuvastatin treatment group had a slightly higher proportion of males (53.1\%) compared with the ezetimibe/simvastatin $10 / 20 \mathrm{mg}(49.7 \%)$ and doubling the statin dose (49.5\%) treatment groups. In non-obese subjects, the mean age $( \pm \mathrm{SD})$ ranged from $64( \pm 9)$ years to 66 $( \pm 8)$ years and the majority of subjects were Caucasian in all 3 treatment groups. There was a higher proportion of Hispanics or Latinos in the non-obese subgroup (23.2\% in the doubling statin group, $24.2 \%$ in the rosuvastatin $10 \mathrm{mg}$ group and $31.9 \%$ in the ezetimibe/simvastatin $10 / 20 \mathrm{mg}$ group) compared with the obese subgroup $(9.7 \%$ in the doubling statin group, $10.5 \%$ in the ezetimibe/simvastatin $10 / 20 \mathrm{mg}$ group and $11.5 \%$ in the rosuvastatin group). Triglyceride levels were higher in obese subjects in all 3 treatment groups (median $=149 \mathrm{mg} / \mathrm{dL}, 136 \mathrm{mg} / \mathrm{dL}$ and $143.5 \mathrm{mg} / \mathrm{dL}$ in the ezetimibe/simvastatin $10 / 20 \mathrm{mg}$, doubling the statin dose and rosuvastatin $10 \mathrm{mg}$ groups, respectively) compared with non-obese subjects (median = $126 \mathrm{mg} / \mathrm{dL}, 126 \mathrm{mg} / \mathrm{dL}$ and $132 \mathrm{mg} / \mathrm{dL}$ in the ezetimibe/ simvastatin $10 / 20 \mathrm{mg}$, doubling the statin dose and rosuvastatin $10 \mathrm{mg}$ groups, respectively). Finally, hs-CRP levels were higher in obese subjects compared with non-obese subjects taking ezetimibe/simvastatin $10 / 20 \mathrm{mg}(2.4 \mathrm{mg} / \mathrm{L}$ vs $1.6 \mathrm{mg} / \mathrm{L})$ and rosuvastatin $10 \mathrm{mg}(2.6 \mathrm{mg} / \mathrm{L} \mathrm{vs} 1.6 \mathrm{mg} /$ 
Table 1 Baseline demographics and clinical characteristics

\begin{tabular}{|c|c|c|c|c|c|c|}
\hline \multirow[b]{2}{*}{ Obese subjects } & \multicolumn{2}{|c|}{ EZ/Simva $10 / 20 \mathrm{mg}$} & \multicolumn{2}{|c|}{ Doubling statin dose } & \multicolumn{2}{|c|}{ Rosuvastatin $10 \mathrm{mg}$} \\
\hline & \multicolumn{2}{|c|}{$n=181$} & \multicolumn{2}{|c|}{$n=93$} & \multicolumn{2}{|c|}{$n=192$} \\
\hline Male & 90 & $(49.7)$ & 46 & $(49.5)$ & 102 & $(53.1)$ \\
\hline Female & 91 & $(50.3)$ & 47 & $(50.5)$ & 90 & $(46.9)$ \\
\hline Age, years Mean (SD) & 63.3 & $(8.2)$ & 63.5 & $(8.5)$ & 63.3 & $(8.2)$ \\
\hline Weight, kg Mean (SD) & 99.3 & $(15.3)$ & 96.2 & $(12.5)$ & 96.5 & (13.3) \\
\hline \multicolumn{7}{|l|}{ Body Mass Index (BMI, $\mathrm{kg} / \mathrm{m}^{2}$ ) } \\
\hline Mean (SD) & 35.4 & $(4.3)$ & 34.6 & $(3.7)$ & 34.6 & (3.7) \\
\hline \multicolumn{7}{|l|}{ Race, n (\%) } \\
\hline American Indian or Alaska Native & 1 & $(0.6)$ & 0 & $(0.0)$ & 1 & $(0.5)$ \\
\hline Black or African American & 4 & $(2.2)$ & 1 & $(1.1)$ & 1 & $(0.5)$ \\
\hline Multi-Racial & 10 & $(5.5)$ & 4 & $(4.3)$ & 8 & $(4.2)$ \\
\hline White & 166 & $(91.7)$ & 88 & $(94.6)$ & 182 & $(94.8)$ \\
\hline \multicolumn{7}{|l|}{ Ethnicity, n (\%) } \\
\hline Hispanic or Latino & 19 & $(10.5)$ & 9 & $(9.7)$ & 22 & $(11.5)$ \\
\hline Not Hispanic or Latino & 162 & $(89.5)$ & 84 & $(90.3)$ & 170 & $(88.5)$ \\
\hline Clinical Characteristics, mg/dL & Mean & SD & Mean & SD & Mean & SD \\
\hline LDL-C & 97.9 & 22.4 & 99.3 & 22.0 & 95.7 & 19.1 \\
\hline Total cholesterol & 179.0 & 30.4 & 180.5 & 27.0 & 178.3 & 24.2 \\
\hline Triglycerides* & 149.0 & 74.4 & 136.0 & 77.2 & 143.5 & 74.4 \\
\hline $\mathrm{HDL}-\mathrm{C}$ & 48.6 & 11.5 & 51.0 & 11.6 & 47.8 & 10.7 \\
\hline Non-HDL-C & 130.4 & 28.3 & 129.4 & 25.8 & 127.5 & 23.6 \\
\hline Apo B & 101.6 & 19.8 & 101.7 & 17.7 & 100.0 & 18.6 \\
\hline Apo A-I & 148.4 & 24.6 & 153.5 & 22.2 & 147.6 & 22.0 \\
\hline hs-CRP* ${ }^{*} \mathrm{mg} / \mathrm{L}$ & 2.4 & 2.9 & 1.9 & 3.2 & 2.6 & 3.7 \\
\hline Non-obese subjects & \multicolumn{2}{|c|}{$n=141$} & \multicolumn{2}{|c|}{$n=69$} & \multicolumn{2}{|c|}{$n=132$} \\
\hline \multicolumn{7}{|l|}{ Sex, n (\%) } \\
\hline Male & 70 & $(49.6)$ & 34 & $(49.3)$ & 80 & $(60.6)$ \\
\hline Female & 71 & $(50.4)$ & 35 & $(50.7)$ & 52 & $(39.4)$ \\
\hline Age, years Mean (SD) & 65.2 & $(9.3)$ & 66.2 & $(7.9)$ & 64.0 & (8.6) \\
\hline Weight, kg Mean (SD) & 73.5 & $(11.0)$ & 76.3 & $(11.5)$ & 76.3 & $(11.5)$ \\
\hline \multicolumn{7}{|l|}{ Body mass index (BMI, $\mathrm{kg} / \mathrm{m}^{2}$ ) } \\
\hline Mean (SD) & 35.4 & $(4.3)$ & 34.6 & $(3.7)$ & 34.6 & $(3.7)$ \\
\hline \multicolumn{7}{|l|}{ Race, n (\%) } \\
\hline American Indian or Alaska Native & 3 & $(2.1)$ & 2 & $(2.9)$ & 4 & (3.0) \\
\hline Black or African American & 1 & $(0.7)$ & 1 & $(1.4)$ & 1 & $(0.8)$ \\
\hline Multi-Racial & 23 & $(16.3)$ & 7 & $(10.1)$ & 16 & $(12.1)$ \\
\hline White & 114 & $(80.9)$ & 59 & $(85.5)$ & 111 & $(84.1)$ \\
\hline \multicolumn{7}{|l|}{ Ethnicity, n (\%) } \\
\hline Hispanic or Latino & 45 & $(31.9)$ & 16 & $(23.2)$ & 32 & $(24.2)$ \\
\hline Not Hispanic or Latino & 96 & $(68.1)$ & 53 & $(76.8)$ & 100 & $(75.8)$ \\
\hline
\end{tabular}


Table 1 Baseline demographics and clinical characteristics (Continued)

\begin{tabular}{|c|c|c|c|c|c|c|}
\hline Clinical characteristics, mg/dL & Mean & SD & Mean & SD & Mean & SD \\
\hline LDL-C & 100.1 & 21.6 & 94.7 & 20.2 & 99.9 & 20.5 \\
\hline Total cholesterol & 180.5 & 30.9 & 173.0 & 26.3 & 178.7 & 28.7 \\
\hline Triglycerides* & 126.0 & 65.1 & 126.0 & 51.2 & 132.0 & 76.3 \\
\hline HDL-C & 52.6 & 15.8 & 50.6 & 12.7 & 50.5 & 13.3 \\
\hline Non-HDL-C & 127.9 & 26.9 & 122.4 & 25.3 & 128.2 & 26.4 \\
\hline Apo B & 101.7 & 20.4 & 98.9 & 20.1 & 101.0 & 20.0 \\
\hline Apo A-I & 152.7 & 32.9 & 153.1 & 28.2 & 149.4 & 27.3 \\
\hline hs-CRP*, mg/L & 1.6 & 2.9 & 2.0 & 2.2 & 1.6 & 2.3 \\
\hline
\end{tabular}

*Data for TG and hs-CRP are presented as median and robust standard deviation. EZ Ezetimibe, Simva Simvastatin.

L) but not in subjects whose baseline statin dose was doubled (1.9 mg/L vs $2.0 \mathrm{mg} / \mathrm{L}$ ).

Regardless of baseline obesity status (obese/non-obese), in this population of high risk diabetic subjects, switching to ezetimibe/simvastatin $10 / 20 \mathrm{mg}$ generally resulted in numerically greater changes in LDL-C compared with doubling the baseline statin dose or switching to rosuvastatin, though the treatment effect was smaller for the comparison of ezetimibe/simvastatin $10 / 20 \mathrm{mg}$ vs. rosuvastatin $10 \mathrm{mg}$ in the obese subgroup (Figure 2). In obese subjects LS mean percent changes from baseline in LDL$\mathrm{C}$ were $-21.6 \%,-10.7 \%$, and $-20.7 \%$ in the ezetimibe/simvastatin $10 / 20 \mathrm{mg}$ group, in the doubling statin group, and in the rosuvastatin $10 \mathrm{mg}$ group, respectively. In nonobese subjects, LS mean percent changes from baseline in LDL-C were $-25.2 \%,-4.9 \%$, and $-17.4 \%$ in the ezetimibe/ simvastatin $10 / 20 \mathrm{mg}$ group, in the doubling statin group, and in the rosuvastatin $10 \mathrm{mg}$ group, respectively. The results of the post hoc sensitivity analysis on log-transformed data were consistent with those of the main analysis on un-transformed data; however, for the comparison vs.

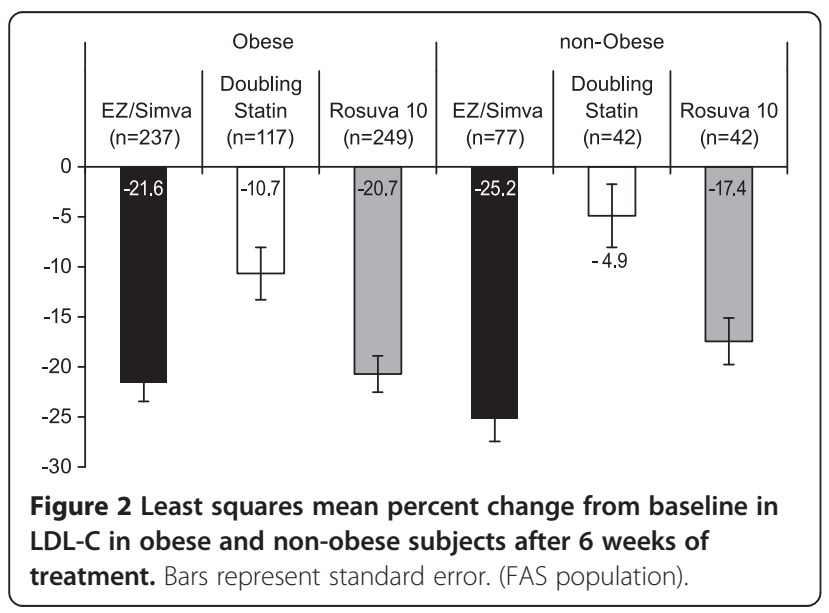

rosuvastatin in obese subjects, the magnitude of the LDL$\mathrm{C}$ difference in the post hoc sensitivity analysis was somewhat higher compared with the main analysis $(-3.2 \%$ in this analysis vs. $-0.9 \%$ in the main analysis).

Achievement of specified lipid targets is shown in Figure 3. In obese and non-obese subjects, more subjects achieved the specified LDL-C targets of $<70 \mathrm{mg} / \mathrm{dL}$ when treated with ezetimibe/simvastatin 10/20 mg (nonobese: $57.4 \%$; obese: $52.2 \%$ ) compared with doubling the baseline statin dose to simvastatin $40 \mathrm{mg}$ or atorvastatin $20 \mathrm{mg}$ (non-obese: $29.0 \%$; obese: $25.6 \%$ ) or switching to rosuvastatin $10 \mathrm{mg}$ (non-obese: $32.5 \%$; obese: $49.2 \%$ ). Similarly, more subjects achieved non-HDL-C $<100 \mathrm{mg} / \mathrm{dL}$ when treated with ezetimibe/simvastatin 10/20 mg (nonobese: $63.2 \%$; obese: $52.2 \%$ ) compared with doubling the baseline statin dose to simvastatin $40 \mathrm{mg}$ or atorvastatin $20 \mathrm{mg}$ (non-obese: 31.9\%; obese: $30.0 \%$ ) or switching to rosuvastatin $10 \mathrm{mg}$ (non-obese: 43.7\%; obese: $46.0 \%$; Figure 3). Finally, a greater percentage of subjects achieved Apo B $<80 \mathrm{mg} / \mathrm{dL}$ when treated with ezetimibe/simvastatin 10/20 mg (non-obese: 50.0\%; obese: $45.8 \%$ ) compared with doubling the baseline statin dose to simvastatin $40 \mathrm{mg}$ or atorvastatin $20 \mathrm{mg}$ (non-obese: $31.9 \%$; obese: $25.6 \%$ ) or switching to rosuvastatin $10 \mathrm{mg}$ (non-obese: $39.2 \%$; obese: 38.1\%; Figure 3).

In both obese and non-obese subjects, treatment with ezetimibe/simvastatin $10 / 20 \mathrm{mg}$ resulted in numerically greater changes in total cholesterol, non-HDL-C, and Apo B compared with doubling the baseline statin dose to simvastatin $40 \mathrm{mg}$ or atorvastatin $20 \mathrm{mg}$ or vs switching to rosuvastatin $10 \mathrm{mg}$ (Table 2 and Figures $4 \mathrm{a}$ and 4b). However, changes in HDL-C and Apo A-I appeared to be similar between treatments in obese subjects (Figure 4a). In non-obese subjects (Figure $4 \mathrm{~b}$ ) changes in triglycerides were numerically greater in the ezetimibe/simvastatin 10/ 20 treatment group compared with the rosuvastatin $10 \mathrm{mg}$ group, while the subjects whose baseline statin dose was doubled showed similar decreases to subjects treated 


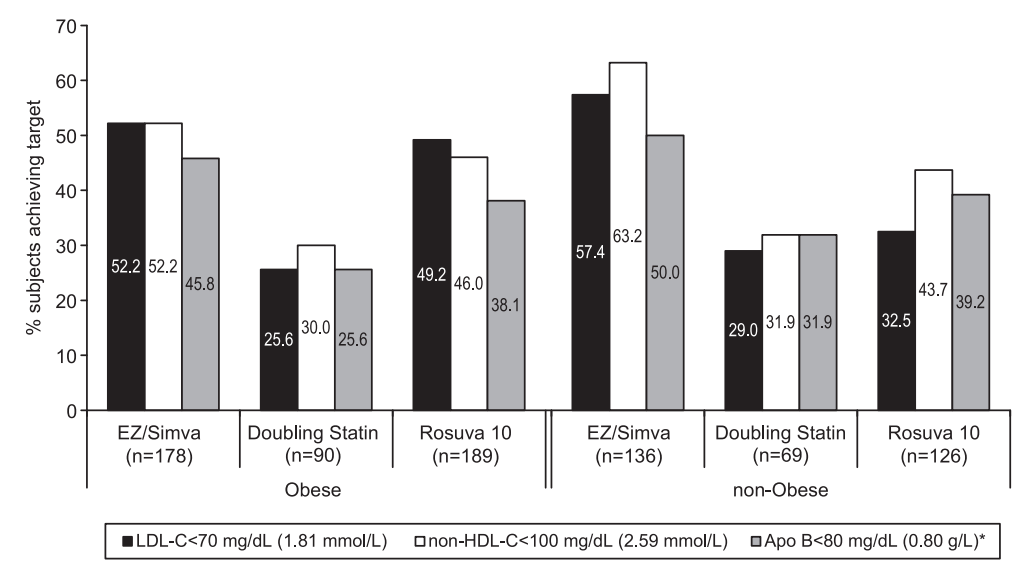

Figure 3 Percent of subjects achieving specified targets after 6 weeks of treatment (FAS population).

with ezetimibe/simvastatin 10/20 mg. In non-obese subjects, changes in HDL-C were similar between treatment groups, and increases in Apo A-I were greater in the ezetimibe/simvastatin $10 / 20 \mathrm{mg}$ vs the doubling the baseline statin dose group (Figure $4 \mathrm{~b}$ ). In both obese and nonobese subjects changes in hs-CRP were numerically greater with rosuvastatin $10 \mathrm{mg}$ vs ezetimibe/simvastatin 10/20 mg (Figures $4 \mathrm{a}$ and $4 \mathrm{~b}$ ). In both obese and non-obese subjects, ezetimibe/simvastatin 10/20 mg was more effective at improving lipid ratios compared with doubling the baseline statin dose to simvastatin $40 \mathrm{mg}$ or atorvastatin $20 \mathrm{mg}$, although the changes were similar to those of rosuvastatin $10 \mathrm{mg}$-treated subjects in both obese and non-obese subjects (Figures $5 \mathrm{a}$ and $5 \mathrm{~b}$ ).

The safety and tolerability profiles were generally similar between treatment groups (Table 3). In the group of obese subjects, $9.9 \%, 9.7 \%$ and $6.8 \%$ of subjects experienced $\geq 1 \mathrm{AE}$ in the ezetimibe/simvastatin group, in the doubling the statin dose group, and the rosuvastatin group, respectively. Three subjects each from the ezetimibe/simvastatin and the doubling the statin dose group discontinued due to an $\mathrm{AE}$, and 2 were due to drug-related AEs. One subject experienced consecutive elevations in AST $>3 \mathrm{X}$ ULN in the rosuvastatin treatment group. There were 4 (2.2\%), 1 (1.1\%) and 3 (1.6\%) reports of gastrointestinal-related AEs in subjects taking ezetimibe/simvastatin group, in subjects who doubled their statin dose, and in the rosuvastatin group, respectively; and 2 reports (1.0\%) of hepatitis-related AEs in rosuvastatin treated subjects. In the non-obese subjects, $10.7 \%, 5.8 \%$ and $11.5 \%$ of subjects experienced $\geq 1 \mathrm{AE}$ in the ezetimibe/simvastatin group, in the doubling the statin dose group, and in the rosuvastatin group, respectively. Four subjects from the ezetimibe/simvastatin group and 1 subject from the rosuvastatin group discontinued due to an $\mathrm{AE}$ and 1 was a drug related $\mathrm{AE}$ in the ezetimibe/simvastatin group. There were no reports of elevations in liver enzymes in the group of non-obese subjects. There were $6(4.3 \%)$ and $4(3.1 \%)$ reports of gastrointestinal-related AEs in subjects taking ezetimibe/ simvastatin and in subjects taking rosuvastatin, respectively; and 2 reports (1.5\%) of hepatitis-related AEs in rosuvastatin-treated subjects. No clinically meaningful differences in change from baseline in blood pressure between the treatment groups were observed in any subgroup.

\section{Discussion}

There have been relatively few studies that have assessed the comparative efficacy of the combination of ezetimibe/

Table 2 Least Squares mean percent change from baseline (95\% confidence interval) in lipids, lipoproteins and hs-CRP

\begin{tabular}{llcccccccc}
\hline & & LDL-C & TC & TG & HDL-C & non-HDL-C & Apo B & Apo A-I & hs-CRP \\
\hline Non-obese & EZ/Simva $(n=77)$ & -25.2 & -13.9 & -4.8 & 1.8 & -19.9 & -16.6 & 2.0 & -7.1 \\
& Doubling statin $(\mathrm{n}=42)$ & -4.9 & -4.1 & -5.3 & -0.2 & -4.8 & -5.6 & -2.3 & -3.7 \\
& Rosuva $10(\mathrm{n}=42)$ & -17.4 & -9.4 & -2.0 & 2.6 & -13.9 & -11.6 & 1.3 & -10.1 \\
\multirow{2}{*}{ Obese } & EZ/Simva $(\mathrm{n}=237)$ & -21.6 & -12.7 & -6.1 & 1.2 & -17.3 & -13.7 & -0.4 & -1.5 \\
& Doubling statin $(\mathrm{n}=117)$ & -10.7 & -5.3 & -0.8 & 1.8 & -8.2 & -8.0 & 0.0 & 1.1 \\
& Rosuva 10 $(\mathrm{n}=249)$ & -20.7 & -11.4 & -4.2 & 1.6 & -16.1 & -12.3 & 0.6 & -9.7 \\
\hline
\end{tabular}



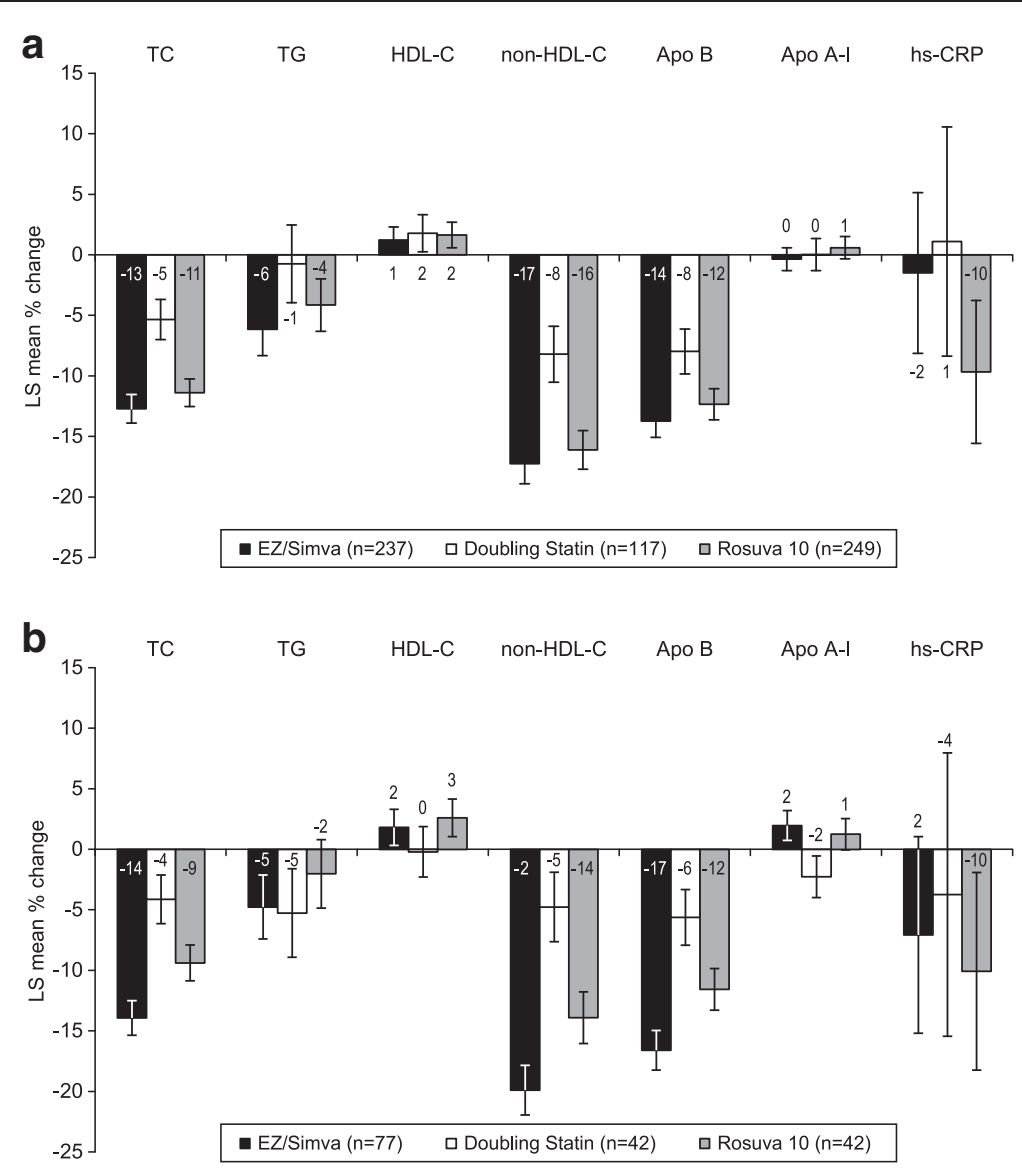

Figure 4 Least squares mean percent change from baseline in lipids, lipoproteins and hs-CRP after 6 weeks of treatment. Bars represent standard error. (FAS population). a. Obese subjects. b. non-obese subjects.

simvastatin with both atorvastatin and rosuvastatin in the same trial. This is the first report of the consistency of treatment effect of all three of these high-potency lipidlowering therapies between subgroups of obese and nonobese diabetic patients in the same trial. With obesity reaching global epidemic proportions and its strong relationship to the development of CVD and atherogenic dyslipidemia, it is important to understand the potential utility of lipid lowering drugs in this population. In this post hoc analysis of subgroups of obese and non-obese diabetic subjects, treatment with ezetimibe/simvastatin $10 / 20 \mathrm{mg}$ resulted in numerically greater reductions in LDL-C compared with rosuvastatin $10 \mathrm{mg}$ only in the non-obese subjects, while the combination of ezetimibe/ simvastatin 10/20 mg resulted in greater changes in LDL$\mathrm{C}$ levels compared with doubling the statin dose in subjects in both subgroups regardless of baseline obesity status (obese/non-obese). In addition, a higher proportion of subjects attained all 3 specified treatment targets (LDLC, non-HDL-C and Apo-B) with ezetimibe/simvastatin
$10 / 20 \mathrm{mg}$ treatment vs doubling the statin dose to atorvastatin $20 \mathrm{mg}$ or simvastatin $40 \mathrm{mg}$ and vs rosuvastatin $10 \mathrm{mg}$ in both subgroups of obese and non-obese subjects. The overall safety and tolerability profile appeared generally comparable and consistent across subgroups and all treatment groups.

The dyslipidemia profile typically observed in obese and diabetic individuals is generally similar and includes high triglycerides $(\geq 200 \mathrm{mg} / \mathrm{dL})$, non-HDL-C, and Apo $B$ levels, increased levels of small, dense LDL-C particles, although often, relatively normal levels of LDL-C, and low HDL-C levels $(<40 \mathrm{mg} / \mathrm{dL}$ in men and $<50 \mathrm{mg} / \mathrm{dL}$ in women) $[7,8]$. As expected, subjects in the obese subgroup had higher mean baseline triglycerides than subjects in the non-obese subgroup; however, these mean levels were lower than the $200 \mathrm{mg} / \mathrm{dL}$ level specified by the NCEP ATP III guidelines that would define patients as having mildly or moderately elevated triglycerides [4]. In addition, they did not have low mean HDL-C levels as would be expected based on typical dyslipidemia 


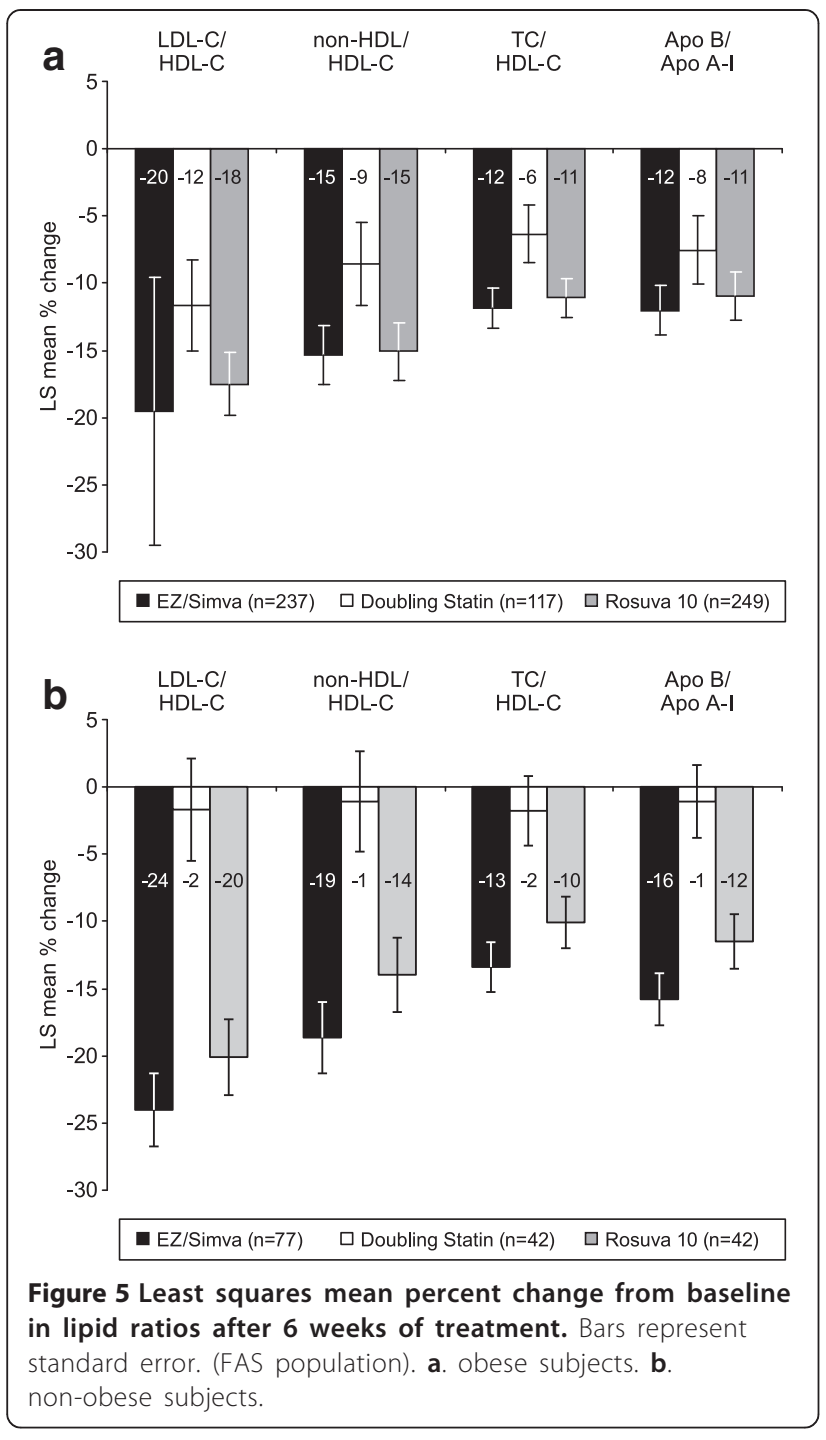

profiles in obese patients $[7,8]$. Finally, mean LDL-C levels in the obese subjects were comparable to those of the non-obese subjects, with mean levels already at or below $100 \mathrm{mg} / \mathrm{dL}$ in all treatment groups, but not reaching the target level of $<70 \mathrm{mg} / \mathrm{dL}$ as specified by the NCEP ATP III guidelines for very high risk individuals. It is important to note that these baseline numbers reflect treated baseline levels, likely resulting from pre-study treatment and/or the 6-week run-in period during which subjects were treated with a starting dose of simvastatin $(20 \mathrm{mg})$ or atorvastatin $(10 \mathrm{mg})$ and during which they agreed to maintain an approved cholesterol- and glucoselowering diet. This pre-study treatment may be why the typical dyslipidemia profile was not observed.

The post hoc analysis results from the subgroup of obese subjects were generally consistent with those of the prespecified analysis results from the overall population with regard to percent change from baseline in LDL-C [14]. Specifically, in the overall population, treatment with the combination of ezetimibe/simvastatin resulted in significantly greater reductions in LDL-C and other lipids compared with doubling the baseline statin dose to atorvastatin $20 \mathrm{mg}$ or simvastatin $40 \mathrm{mg}$, but not compared with rosuvastatin $10 \mathrm{mg}$. However, in the subgroup of non-obese subjects in the current post hoc analysis, greater reductions in LDL-C were observed in favor of ezetimibe/simvastatin $10 / 20 \mathrm{mg}$ vs doubling the baseline statin dose to atorvastatin $20 \mathrm{mg}$ or simvastatin $40 \mathrm{mg}$ and vs rosuvastatin $10 \mathrm{mg}$. These results are consistent with the sensitivity analyses of the overall population which showed statistically significant differences between the combination treatment and rosuvastatin $10 \mathrm{mg}(-27.58$ vs $-22.20 ; p=0.002$ ). Moreover, the current sensitivity analysis results are consistent not only with the current exploratory analysis, but also with the primary analysis; however, for the ezetimibe/simvastatin $10 / 20 \mathrm{mg}$ vs. rosuvastatin $10 \mathrm{mg}$ comparison, the magnitude of the difference appeared to be somewhat higher compared with the main analysis. A previous post hoc analysis conducted in obese and non-obese subjects reported greater reductions with ezetimibe/simvastatin $10 / 20 \mathrm{mg}$ vs. rosuvastatin $10 \mathrm{mg}$ in both subgroups, however, those patients were not all diabetic [15]. In addition, the results of a study by Furman and colleagues in high risk patients $(\mathrm{BMI}=30$ $31 \mathrm{~kg} / \mathrm{m}^{2}$ ) who had not achieved LDL-C $<100 \mathrm{mg} / \mathrm{dL}$ while treated with simvastatin demonstrated significantly greater reductions in LDL-C with the combination of ezetimibe/ simvastatin vs rosuvastatin and vs atorvastatin $(\mathrm{p}<0.05)$ using average doses of $9 / 64 \mathrm{mg}$ ezetimibe/simvastatin, $18 \mathrm{mg}$ rosuvastatin, and $68 \mathrm{mg}$ atorvastatin, which is consistent with the numerically greater reductions in most lipids vs doubling the statin dose to simvastatin $40 \mathrm{mg}$ or atorvastatin $20 \mathrm{mg}$ or vs rosuvastatin $10 \mathrm{mg}$ observed in the current analysis [16]. One explanation for the inconsistencies between this group of subjects and those in previous studies may be differences in metabolism due to the presence of diabetes, which has been associated with high cholesterol synthesis and reduced cholesterol absorption efficiency regardless of obesity [17]. Larger trials to compare obese and non-obese diabetic patients are needed to fully assess these questions.

Although there is resounding evidence that LDL-C lowering reduces cardiovascular risk, there are also data to demonstrate that the typical dyslipidemia profile observed in diabetic patients, which is shared by obese patients, often results in residual risk even after LDL-C targets are achieved. Consequently, it is essential to consider secondary lipoprotein targets to reduce the atherogenic burden in diabetic patients once they have reached their individual LDL-C goal. Specifically, elevated Apo B and non-HDL-C 
Table 3 Summary of safety data (APaT population)

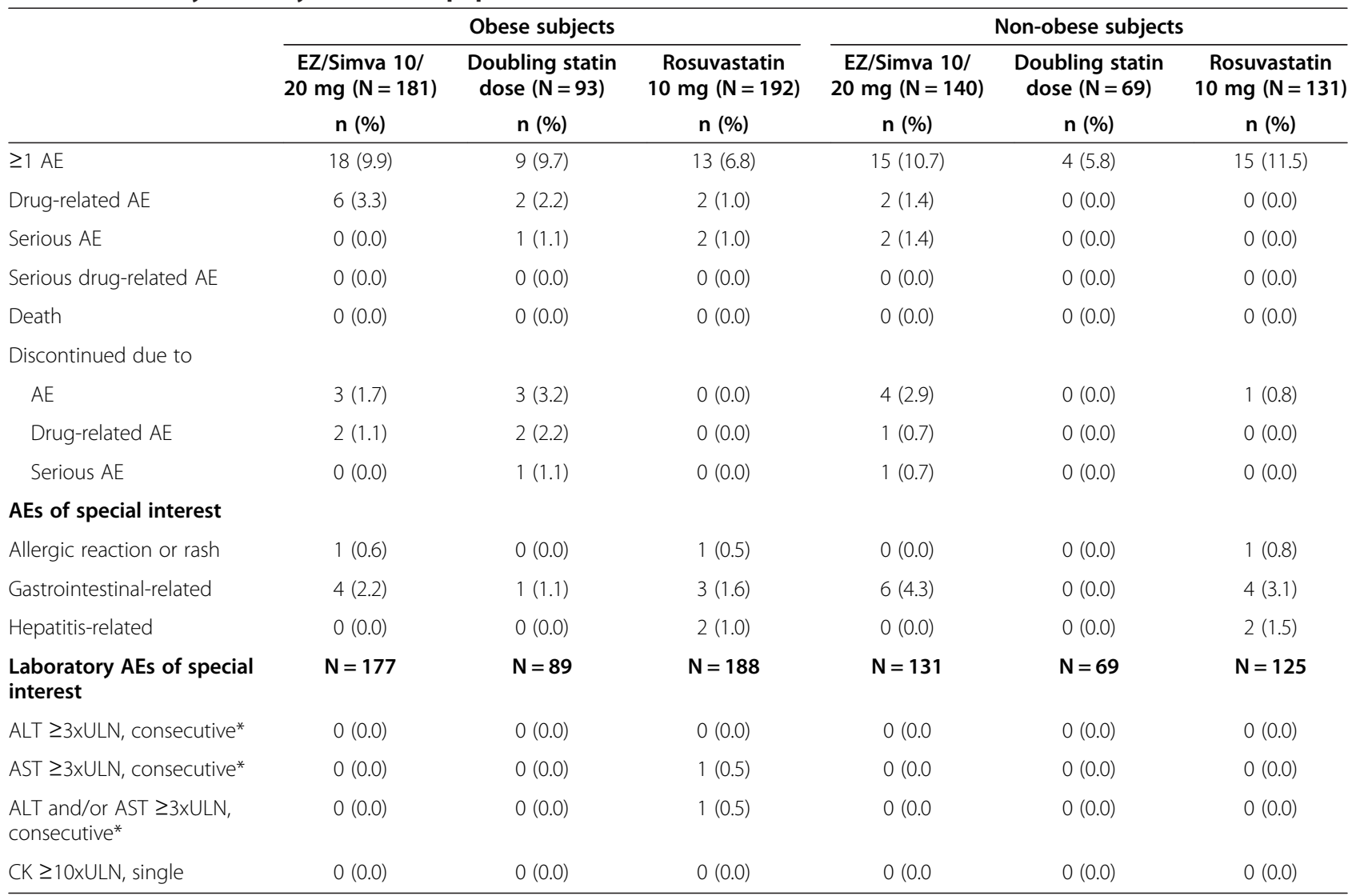

*Consecutive includes those patients with (a) measurement $\geq 3 \times$ ULN observed at 2 or more consecutive visits (b) a single, last measurement $\geq 3 \times$ ULN, or (c) a measurement $\geq 3 \times$ ULN followed by a measurement $<3 \times$ ULN that was taken more than 2 days after the last dose of study medication.

$A E$ adverse event, $A L T$ alanine aminotransferase, AST aspartate aminotransferase, CK creatine kinase, EZ ezetimibe, Simva Simvastatin, ULN upper limit of normal.

are both recommended treatment targets for very high risk patients $[4,9]$. In this study, regardless of baseline obesity status (obese/non-obese), the combination of ezetimibe/ simvastatin treatment resulted in higher percentages of diabetic patients achieving not only the aggressive LDL-C target of $<70 \mathrm{mg} / \mathrm{dL}$, but also non-HDL-C $<100 \mathrm{mg} / \mathrm{dL}$ and Apo-B $<80 \mathrm{mg} / \mathrm{dL}$ treatment targets compared with doubling the baseline statin dose and compared with rosuvastatin $10 \mathrm{mg}$. This result is consistent with a previous post hoc analysis of obese and non-obese subjects (of which only $1 / 3$ were diabetic) in which higher percentages of patients achieved specified LDL-C, non-HDL-C and Apo $B$ levels when treated with combination ezetimibe/simvastatin compared with rosuvastatin monotherapy [15].

The safety and tolerability profiles were generally consistent between treatments and between subgroups, although slightly more subjects taking ezetimibe/simvastatin 10/ $20 \mathrm{mg}$ discontinued due to AEs compared with the other treatment groups. Previous trials comparing the safety profile of ezetimibe combined with simvastatin vs statins, including a post hoc analysis in obese and non-obese subjects do not suggest that there are significant tolerability differences between these treatments $[15,18]$; however, the use of the highest dose $(80 \mathrm{mg})$ of simvastatin has been restricted by the US Food and Drug Administration due to the higher risk of myopathy/rhabdomyolysis [19]. Moreover, previous studies in high-risk diabetic subjects have not indicated tolerability issues with the combination treatment $[10,11]$.

This study was an exploratory, post hoc analysis and did not include statistical comparisons, nor multiplicity adjustments. Moreover, the study was not powered to detect very rare adverse events and was of relatively short duration. Therefore, the efficacy and safety results should be interpreted with some caution.

These results suggest that regardless of baseline obesity status (obese/non-obese), switching to combination ezetimibe/simvastatin $10 / 20 \mathrm{mg}$ provides a well-tolerated lipid-lowering effect in diabetic hypercholesterolemic subjects who have not achieved a goal of LDL-C $<70 \mathrm{mg} \mathrm{mg} /$ dl $(1.81 \mathrm{mmol} / \mathrm{L})$ while on simvastatin $20 \mathrm{mg}$ or atorvastatin $10 \mathrm{mg}$. 


\section{Competing interests}

MEH, RM, PB and JT are employees of Merck \& Co, Inc. and may own stock or hold stock options in the company; JBR has a Research grant and has served on the Speaker's Bureau for Merck \& Co., Inc.; JGJ received honoraria from Merck as a speaker for diabetes in Central America; PV received a research grant from Merck \& Co, Inc., HV received a research grant from Merck \& Co, Inc.

\section{Authors' contributions}

$J R, J G J, V P$ and HV collected or assembled the data, provided substantive suggestions for revision on subsequent iterations of the manuscript, and provided study materials or patients. RM conceived, designed or planned the study, performed or supervised analyses, interpreted the results, provided substantive suggestions for revision on subsequent iterations of the manuscript, and provided statistical expertise. MEH interpreted the results, wrote sections of the initial draft, and provided administrative, technical, or logistic support. PB conceived, designed and planned the study, and provided substantive suggestions for revision on subsequent iterations of the manuscript. JT interpreted the results, provided substantive suggestions for revision on subsequent iterations of the manuscript, and provided administrative, technical, or logistic support. All authors reviewed and approved the final version of the manuscript.

\section{Acknowledgements}

This trial is registered at http://www.clinicaltrials.gov/: NCT00862251 and was funded by Merck \& Co, Inc., Whitehouse Station, NJ. Editorial assistance was provided by Jennifer Rotonda, PhD, of Merck \& Co, Inc., Whitehouse Station, NJ, USA.

\section{Author details}

${ }^{1}$ Clinical Research of South Florida, Coral Gables, FL, USA. ${ }^{2}$ Hospital CIMA San Jose, Escazu, San Jose, Costa Rica. ${ }^{3}$ University of Latvia, Riga, Latvia. ${ }^{4}$ Viljandi Hospital, Vildjandimaa, Estonia. ${ }^{5}$ MSD Belgium, Brussels, Belgium. ${ }^{6}$ Merck \&

Co, Inc., Whitehouse Station, NJ, USA.

Received: 23 April 2013 Accepted: 8 July 2013

Published: 16 July 2013

\section{References}

1. Haffner SM, Lehto S, Ronnemaa T, Pyorala K, Laakso M: Mortality from coronary heart disease in subjects with type 2 diabetes and in nondiabetic subjects with and without prior myocardial infarction. N Engl J Med 1998, 339:229-234.

2. Simons LA, Simons J: Diabetes and coronary heart disease. N Engl J Med 1998, 339:1714-1715.

3. Clinical guidelines on the identification, evaluation, and treatment of overweight and obesity in adults: executive summary. Expert Panel on the Identification, Evaluation, and Treatment of Overweight in Adults. Am J Clin Nutr 1998, 68:899-917.

4. Expert panel on detection evaluation and treatment of high blood cholesterol in adults: Executive Summary of The Third Report of The National Cholesterol Education Program (NCEP) Expert Panel on Detection, Evaluation, And Treatment of High Blood Cholesterol In Adults (Adult Treatment Panel III). JAMA 2001, 285:2486-2497.

5. Genest J, McPherson R, Frohlich J, Anderson T, Campbell N, Carpentier A, Couture P, Dufour R, Fodor G, Francis GA, Grover S, Gupta M, Hegele RA, Lau DC, Leiter L, Lewis GF, Lonn E, Mancini GB, Ng D, Pearson GJ, Sniderman A, Stone JA, Ur E: Canadian Cardiovascular Society/Canadian guidelines for the diagnosis and treatment of dyslipidemia and prevention of cardiovascular disease in the adult - 2009 recommendations. Can J Cardiol 2009, 2009(25):567-579.

6. Fourth Joint Task Force of the European Society of Cardiology and Other Societies on Cardiovascular Disease Prevention in Clinical Practice: European guidelines on cardiovascular disease prevention in clinical practice: executive summary. Eur I Cardiovasc Prev Rehabil 2007, 14:E1-E40.

7. Hoenig MR, Kostner KM, Read SJ, Walker PJ, Atherton JJ: Implications of the obesity epidemic for statin therapy: shifting cholesterol metabolism to a high synthesis and low dietary absorption state. Endocr Metab Immune Disord Drug Targets 2007, 7:153-166.

8. Howard BV, Ruotolo G, Robbins DC: Obesity and dyslipidemia. Endocrinol Metab Clin North Am 2003, 32:855-867.
9. Brunzell JD, Davidson M, Furberg CD, Goldberg RB, Howard BV, Stein JH, Witztum JL: Lipoprotein management in patients with cardiometabolic risk: consensus statement from the American Diabetes Association and the American College of Cardiology Foundation. Diabetes Care 2008, 31:811-822.

10. Bardini G, Giorda CB, Pontiroli AE, Le Grazie C, Rotella CM: Ezetimibe + simvastatin versus doubling the dose of simvastatin in high cardiovascular risk diabetics: a multicenter, randomized trial (the LEAD study). Cardiovasc Diabetol 2010, 9:20.

11. Goldberg RB, Guyton JR, Mazzone T, Weinstock RS, Polis A, Edwards P, Tomassini JE, Tershakovec AM: Ezetimibe/simvastatin vs atorvastatin in patients with type 2 diabetes mellitus and hypercholesterolemia: the VYTAL study. Mayo Clin Proc 2006, 81:1579-1588.

12. McCormack T, Harvey P, Gaunt R, Allgar V, Chipperfield R, Robinson P: Incremental cholesterol reduction with ezetimibe/simvastatin, atorvastatin and rosuvastatin in UK General Practice (IN-PRACTICE): randomised controlled trial of achievement of Joint British Societies (JBS-2) cholesterol targets. Int J Clin Pract 2010, 64:1052-1061.

13. Leiter LA, Betteridge DJ, Farnier M, Guyton JR, Lin J, Shah A, JohnsonLevonas AO, Brudi P: Lipid-altering efficacy and safety profile of combination therapy with ezetimibe/statin vs. statin monotherapy in patients with and without diabetes: an analysis of pooled data from 27 clinical trials. Diabetes Obes Metab 2011, 13:615-628.

14. Rosen JB, Jimenez JG, Pirags V, Vides H, Hanson ME, Massaad R, McPeters G, Brudi P, Triscari J: A comparison of efficacy and safety of an ezetimibe/ simvastatin combination compared with other intensified lipid-lowering treatment strategies in diabetic patients with symptomatic cardiovascular disease. Cardiovasc Drugs Ther 2012, 10:277-286.

15. Missault L, Averna M, Farnier M, Vaverkova H, Viikari J, Dong Q, Shah A, Johnson-Levonas A, Taggart W, Brudi P: Efficacy of Ezetimibe/Simvastatin 10/20 mg Versus Rosuvastatin $10 \mathrm{mg}$ in High-Risk Patients With or Without Obesity. Combination Products in Therapy 2011, 1:1-15.

16. Furman A, Meier UL, Malmstrom RA, Lopez JR, Schaefer S: Comparative efficacy of ezetimibe/simvastatin, rosuvastatin, and atorvastatin in uncontrolled hyperlipidemia patients. Am J Manag Care 2011, 17:538-544.

17. Simonen PP, Gylling HK, Miettinen TA: Diabetes contributes to cholesterol metabolism regardless of obesity. Diabetes Care 2002, 25:1511-1515.

18. Davidson MH, Maccubbin D, Stepanavage M, Strony J, Musliner T: Striated muscle safety of ezetimibe/simvastatin (Vytorin). Am J Cardiol 2006 , 97:223-228.

19. US Food and Drug Administration: FDA Drug Safety Communication: New restrictions, contraindications, and dose limitations for Zocor (simvastatin) to reduce the risk of muscle injury. Silver Springs, MD: US Department of Health \& Human Services; 2013.

doi:10.1186/1476-511X-12-103

Cite this article as: Rosen et al:: Consistency of effect of ezetimibe/ simvastatin compared with intensified lipid-lowering treatment strategies in obese and non-obese diabetic subjects. Lipids in Health and Disease 2013 12:103.

\section{Submit your next manuscript to BioMed Central and take full advantage of:}

- Convenient online submission

- Thorough peer review

- No space constraints or color figure charges

- Immediate publication on acceptance

- Inclusion in PubMed, CAS, Scopus and Google Scholar

- Research which is freely available for redistribution 